\title{
Caracterização da violência física sofrida por prostitutas do interior piauiense
}

\author{
Characterization of physical violence experienced by prostitutes living inside the state of Piauí \\ Caracterización de la violencia física sufrida por prostitutas del interior del estado de Piauí
}

\section{Jardeliny Corrêa da Penha', Sheyla Dayana Coelho Cavalcanti", Simone Barroso de Carvalho", Priscila de Souza Aquino"II, Dayze Djanira Furtado de Galiza ${ }^{\prime V}$, Ana Karina Bezerra Pinheirov}

\author{
' Universidade Federal do Ceará, Programa de Pós-Graduação Cuidados Clínicos em \\ Enfermagem e Saúde (Mestranda). Fortaleza-CE, Brasil. \\ "Universidade Federal do Piauí, Curso de Bacharelado em Enfermagem (Graduanda). Teresina-Pl, Brasil. \\ I' Universidade Federal do Ceará, Centro de Ciências da Saúde, Departamento de Enfermagem. Fortaleza-CE, Brasil. \\ IV Universidade Federal do Piauí, Campus Senador Helvídio Nunes de Barros. Picos-PI, Brasil. \\ ${ }^{v}$ Universidade Federal do Ceará, Faculdade de Farmácia Odontologia e Enfermagem, Departamento de Enfermagem, \\ Programa de Pós-Graduação em Enfermagem. Fortaleza-CE, Brasil.
}

\section{Submissão: 08-08-2011 Aprovação: 24-01-2013}

\section{RESUMO}

Trata-se de um estudo descritivo-exploratório, com abordagem quantitativa, que teve por objetivo caracterizar a violência física sofrida por prostitutas piauienses e identificar a prevalência deste agravo. Participaram do estudo 76 prostitutas cadastradas na Associação das Profissionais do Sexo de Picos, município do estado do Piauí. A coleta de dados foi realizada nas zonas de prostituição e na Associação, no período de setembro a outubro de 2010. Os resultados evidenciaram que a maioria das prostitutas era jovem, de baixa renda, baixa escolaridade, apresentava tempo de prostituição superior há dois anos $(50 \%)$, sendo acometidas principalmente pela violência psicológica $(60,5 \%)$, seguida da física $(30,2 \%)$. Os agressores eram conhecidos das vítimas e as mulheres dificilmente realizaram a denúncia. Os resultados foram esclarecedores e levaram a afirmar que é comum a ocorrência de violência em mulheres prostitutas, já que estas trabalham em lugares determinantes de atos violentos.

Descritores: Prostituição; Violência Contra a Mulher; Enfermagem.

\section{ABSTRACT}

This is a descriptive exploratory study with a quantitative approach, which aimed to characterize the physical violence suffered by prostitutes of Piauí and identify the prevalence of this disease. The study included 76 prostitutes registered in the Association of Sex Professionals of Picos, county of the state of Piauí, Brazil. The data collection was conducted in the areas of prostitution and in the association, from September to October 2010. The results showed that most prostitutes were young, with low income, low education, had more than two years in prostitution $(50 \%)$, being mainly affected by psychological violence $(60.5 \%)$ followed by physical $(30.2 \%)$. The aggressors were known to the victims and women hardly made the complaint. The results were enlightening and led to affirm that it is common the occurrence of violence in women prostitutes, because they work in places determinants of violent acts.

Key words: Prostitution; Violence Against Women; Nursing.

\section{RESUMEN}

Es un estudio descriptivo exploratorio con enfoque cuantitativo, cuyo objetivo fue caracterizar la violencia física sufrida por las prostitutas del Piauí y determinar la prevalencia de esta enfermedad. El estudio incluyó 76 prostitutas registradas en la Asociación de Profesionales del Sexo de Picos, município del estado de Piauí, Brasil. La recolección de datos se llevó a cabo en las áreas de la prostitución y la Asociación, entre septiembre y octubre de 2010. Los resultados mostraron que la mayoría de las prostitutas eran jóvenes, con nivel educativo bajo, tienen tiempo en la prostitución mayor que dos años $(50 \%)$, siendo principalmente afectadas por la violencia psicológica $(60,5 \%)$, seguido de física $(30,2 \%)$. Los atacantes eran conocidos de las víctimas y las mujeres rara vez presentan la queja. Los resultados fueron esclarecedores y llevaron a afirmar que la ocurrencia de la violencia en las mujeres prostitutas es común, ya que trabajan en lugares determinantes de los hechos violentos.

Palabras clave: Prostitución; Violencia Contra las Mujeres; Enfermería. 


\section{INTRODUÇÃO}

Entre as atividades comerciais mais antigas da história da humanidade está a prostituição, considerada, por alguns estudiosos, como a mais anosa. O exercício do meretrício consiste em prática sexual remunerada, a qual, geralmente, não requer a existência de vínculo afetivo entre as pessoas que a realizam, ou seja, há uma troca de prazeres sexuais por bens materiais.

$\mathrm{Na}$ antiguidade, a prostituição configurava uma espécie de ritual de iniciação de meninas quando atingiam a puberdade e, em algumas civilizações, as prostitutas recebiam honras e presentes em troca de favores sexuais ${ }^{(1)}$.

A prostituição constitui-se, pois, em uma prática milenar que tradicionalmente tem subvertido o exercício 'controlado' da sexualidade via instituições sociais. Tentativas de controle foram implementadas no passado, variando da satanização, isto é, o controle exercido pela instituição religiosa, passando pela proibição expressa em códigos civis, e chegando, no Brasil, à demanda pela sua legalização, como atividade

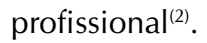

Para se chegar ao exercício do trabalho sexual existem diversas circunstâncias, entre elas o fator econômico que se relaciona com: serem mulheres separadas e donas de casa; que tenham sido mães sem um companheiro estável ou sem apoio econômico do pai de seus filhos; ou que necessitem de renda para custeio de cursos universitários. Ou seja, estas muIheres se sentem responsáveis pela sobrevivência da família e delas mesmas ${ }^{(3)}$. Outras causas são: a necessidade e a luta pela sobrevivência nos grandes centros urbanos, uma forma aparentemente mais fácil de sobreviver; o baixo nível de escolaridade, com dificuldade de ascensão por outros serviços; bem como pela constante necessidade de obtenção material, mesmo em condição financeira estável, e busca por experiências exitosas $^{(4)}$.

Ademais, é perceptível também que essas mulheres constituem um grupo que vive, secularmente, à margem da sociedade, sendo estigmatizadas e vítimas constante de violência, seja ela física, psicológica ou sexual. Tais agressões podem ser afirmadas pela tamanha exposição das prostitutas; atuação das mesmas em ambientes inseguros; ou ainda pela sensação do cliente de poder sobre o corpo dessas mulheres, visto a realização do pagamento pela prática sexual. Em termos gerais, a violência contra a mulher é um fenômeno universal que atinge todas as etnias, religiões e culturas, ocorrendo em populações de diferentes níveis de desenvolvimento econômico e social, sem excluir as prostitutas ${ }^{(5)}$.

Com isso, define-se violência como o uso de palavras ou ações que machucam as pessoas ou que provoque a ruptura de qualquer forma de integridade do indivíduo abordado, podendo ser categorizada em violência psicológica, caracterizada por atos de constrangimentos, ofensas, e/ou coações; violência sexual, quando a vítima é obrigada a satisfazer os desejos sexuais do agressor; e violência física, marcada pela presença de ações que atingem o corpo da vítima. No Brasil, as mulheres tem sido as principais vítimas dessas formas de violência, e ao longo do século XX estas adquiriram várias designações: nos anos 50, como violência intrafamiliar; seguida de violência contra a mulher na década de 70; como violência doméstica em 1980; e a partir de 1990, como violência de gênero ${ }^{(6-7)}$.

No Brasil, a agressão à mulher é considerado um problema de Saúde Pública, pois gera grande impacto na vida do indivíduo e coletividade, representando uma das causas freqüentes de morbimortalidade das vítimas. E em virtude dessa realidade em âmbito nacional, foi sancionada, em 07 de agosto de 2006, a Lei n 11.340, conhecida como Lei Maria da Penha, que cria mecanismos para coibir a violência doméstica e familiar contra a mulher, e dispõe sobre a criação dos Juizados de Violência Doméstica e Familiar contra a Mulher ${ }^{(8)}$.

Segundo o Ministério da Saúde, o atendimento à mulher vítima de violência nos serviços de saúde deve incluir entrevista, registro da história da agressão, exame clínico e ginecológico, exames complementares e acompanhamento psicológico, bem como, e se necessário, a realização da anticoncepção de emergência, devendo ser explicado o que será realizado em cada etapa do atendimento e a importância de cada medida. Deve-se ainda respeitar a autonomia e o sigilo da vítima, acatando à eventual recusa de algum procedimento. E nos casos de gravidez, suspeita ou confirmada, deve-se considerar o desejo ou não da interrupção da mesma ${ }^{(5)}$.

Com isso, para promover ações e compromissos para prevenção da violência, os profissionais de saúde, em especial os enfermeiros, devem atuar principalmente na atenção básica, com o intuito de promover reflexões acerca de crenças, tabus e valores culturais que envolvam os papéis de gênero e poder na família; buscar a deslegitimação institucional e/ou social da violência; promover modelos de não violência; valorizar o papel ativo da comunidade na resolução não violenta de conflitos; buscar a adoção e respeito à legislação internacional de direitos humanos; e favorecer o acesso a serviços adequados e apoio institucional às famílias e pessoas vulneráveis à situação de violência ${ }^{(9)}$.

Em face de todo o exposto e considerando-se, pois, a violência contra a mulher como problema de Saúde Pública, objetivou-se realizar um estudo que permitisse conhecer a realidade das prostitutas da cidade de Picos-PI, a fim de caracterizar a violência física sofrida por essas prostitutas, bem como identificar a prevalência deste agravo.

\section{REVISÃO DA LITERATURA}

Em pesquisa realizada com os descritores: violência contra a mulher, saúde da mulher, prostituição e enfermagem, nas bases de dados SciELO, LILACS, BDENF e Pubmed, foi possível encontrar trabalhos que tratam de agressões contra a mulher em seus diversos aspectos, pois é fundamental rever conceitos e discussões acerca do assunto tratado, a fim de tornar prática as políticas que contemplam a saúde da mesma.

Em nível mundial, um estudo realizado em 15 cidades de 10 países entrevistou 24.097 mulheres a respeito de violências física e sexual praticadas por parceiro íntimo. A prevalência de violência física, ao menos uma vez na vida, variou de $13 \%$, em uma cidade do Japão; até $61 \%$, na província do Peru; nas demais cidades a média foi ente $23 \%$ a $49 \%{ }^{(10)}$. 
Os casos de violência contra a mulher, em âmbito nacional, tinham como base, até 2002, o Programa Nacional de Combate à Violência contra a Mulher, que era gerenciado pela Secretaria de Estado de Direitos da Mulher (SEDIM), do Governo Federal. O mesmo apoiava a construção de Casas Abrigo e a criação de Delegacias Especializadas no Atendimento à Mulher (DEAM).

No ano de 2003, com a criação da Secretaria Especial de Políticas para as Mulheres (SPM) tornou-se necessária a formulação da Política Nacional de Enfrentamento à Violência contra as Mulheres, redirecionando, assim, as ações do programa. E com a realização da I Conferência Nacional de Políticas para as Mulheres, em 2004, houve uma reafirmação da política, o que levou ao estabelecimento do enfrentamento de todas as formas de violência contra as mulheres.

Em estudo realizado no estado de São Paulo e na Zona da Mata Pernambucana (ZMP), foram entrevistadas, na primeira, 940 mulheres e, na segunda localidade, 1.188, que tiveram ao menos um parceiro íntimo na vida. Em São Paulo, a prevalência de violência física e/ou sexual durante a vida foi de $28,9 \%$, e na ZMP, 36,9\% ${ }^{(11)}$. E um centro de saúde distrital de Ribeirão Preto (SP), em entrevistas com 265 mulheres, que tinham, em média, 34,6 anos de idade, 26,4\% delas, alguma vez na vida, foram vítimas de violência física. Destas $40 \%$ relataram que a violência ocorreu nos últimos 12 meses $^{(12)}$.

Em estudo desenvolvido com 40 prostitutas do município de Sobral (CE), 13 (62\%) disseram que sofreram, às vezes, atitudes violentas e $8(38 \%)$ afirmaram que são violentadas sempre, com ocorrência de violência física em 12 (30\%), sexual em 5 (12,5\%) e psicológica em 4 (10\%) das mulheres ${ }^{(13)}$.

Diante dos elevados números, a violência contra a mulher constitui também sério problema de Saúde Pública por gerar forte impacto sobre a saúde física, mental, e sobre o bem-estar, das mulheres, dos filhos e demais membros da família ${ }^{(5)}$. Logo, é perceptível que é difícil resolver um problema somente na sua singularidade ou no nível da atenção básica. Prontamente, os casos de violência contra a mulher exigem abordagem e intervenção interdisciplinares e intersetoriais, o que torna necessária a discussão da questão tratada no cotidiano dos serviços de saúde, a definição de prioridades para capacitar os profissionais e o estabelecimento de parcerias com outros serviços ${ }^{(14)}$.

\section{METODOLOGIA}

Trata-se de estudo do tipo descritivo-exploratório, com abordagem quantitativa. O público-alvo para a investigação do estudo foram prostitutas cadastradas na Associação das Profissionais do Sexo do município de Picos-PI (APROSEP), que possui 450 mulheres associadas, distribuídas em 850 pontos de prostituição catalogados pela associação.

A APROSEP foi fundada em 2004 com a finalidade de obtenção de melhor qualidade de vida e de trabalho para as prostitutas. Os critérios de inclusão consistiam em ser prostitutas em exercício na cidade de Picos-PI, estar associada à APROSEP, estar disponível para participar da pesquisa no momento da investigação e ter idade acima dos 18 anos. Como critérios de exclusão, foram definidos: ser portadora de algum tipo de distúrbio mental e está em uso de substâncias alucinógenas ou em exercício da atividade profissional no momento da entrevista.

O total de participantes do estudo que contemplou os critérios de inclusão foi 76 prostitutas. Para a coleta de dados foi utilizado um formulário estruturado elaborado com base na ficha de notificação compulsória de violência doméstica, sexual e/ou outras violências, do Ministério da Saúde, adaptado para os objetivos do estudo. A aplicação do mesmo foi realizada nas zonas de prostituição, bem como na APROSEP, que se localiza próximo aos prostíbulos. O período de coleta de dados foi de setembro a outubro de 2010. Os dados encontrados foram tabulados no Microsoft Excel, e analisados pelo programa estatístico SPSS (Statistical Package for Social Sciences), versão 17.0.

O estudo foi submetido, inicialmente, ao Comitê de Ética em Pesquisa da Universidade Federal do Piauí (UFPI), a fim de contemplar as diretrizes e normas regulamentadoras de pesquisas envolvendo seres humanos, propostas pela Resolução 196/96 do Conselho Nacional de Saúde, sendo aprovado sob Parecer $n^{\circ}$ 0176.0.045.00-10.

\section{RESULTADOS}

O presente estudo contou com a participação de 76 prostitutas cadastradas na APROSEP. As características sociodemográficas, como idade, escolaridade, renda e tempo de prostituição foram dispostas na tabela 1 .

Tabela 1 - Distribuição dos dados sociodemográficos das prostitutas entrevistadas. Picos-PI, set/out 2010.

\begin{tabular}{|c|c|c|}
\hline Dados sociodemográficos $(n=76)$ & $\mathbf{N}$ & $\%$ \\
\hline \multicolumn{3}{|l|}{ Faixa etária (em anos) } \\
\hline Entre 18 e 19 & 7 & 9,2 \\
\hline Entre 20 e 30 & 43 & 56,6 \\
\hline Entre 31 e 40 & 17 & 22,4 \\
\hline Entre 41 e 50 & 8 & 10,5 \\
\hline Acima de 50 & 1 & 1,3 \\
\hline \multicolumn{3}{|l|}{ Escolaridade (em anos) } \\
\hline Analfabeta & 4 & 5,3 \\
\hline Entre 1 e 3 & 2 & 2,6 \\
\hline Entre 4 e 7 & 25 & 32,9 \\
\hline Entre 8 e 11 & 30 & 39,5 \\
\hline Acima de 11 & 9 & 11,8 \\
\hline Não responderam & 6 & 7,9 \\
\hline \multicolumn{3}{|l|}{ Renda individual mensala } \\
\hline Menos de $1 / 2$ salário mínimo & 10 & 13,2 \\
\hline De $1 / 2$ a 1 salário mínimo & 32 & 42,1 \\
\hline Mais de 1 a 3 salários mínimos & 26 & 34,2 \\
\hline Mais de 3 salários mínimos & 8 & 10,5 \\
\hline \multicolumn{3}{|l|}{ Tempo de prostituição $(n=76)$} \\
\hline$>$ de 3 meses & 5 & 6,6 \\
\hline De 3 a 6 meses & 7 & 9,2 \\
\hline Mais de 6 meses a 1 ano & 12 & 15,8 \\
\hline Mais de 1 a 2 anos & 14 & 18,4 \\
\hline Mais de 2 anos & 38 & 50 \\
\hline
\end{tabular}

aSalário mínimo vigente: $R \$ 510,00$. 
Conforme percebeu-se, a maioria das entrevistadas apresentava idade até 30 anos, o que denota uma população jovem, em plena capacidade laboral, vivendo da prostituição. Em sua maioria, as mulheres participantes da investigação possuíam escolaridade superior a 8 anos de estudo e renda individual mensal até 1 salário mínimo, com até 2 anos de exercício do meretrício.

Os dados concernentes à prevalência da violência na história de vida das entrevistadas, bem como as informações sobre os episódios do tipo de violência sofrida foram dispostos na tabela 2

Tabela 2 - Distribuição dos dados referentes à prevalência e aos episódios de violência da história de vida das prostitutas. Picos-PI, set/out 2010.

\begin{tabular}{lcc}
\hline Prevalência e episódios de violência & N & \% \\
\hline Vítimas de violência $(\mathbf{n}=\mathbf{7 6})$ & 31 & 40,8 \\
Tipo de violência sofridab $\mathbf{( n = 4 3 )}$ & 13 & 30,2 \\
Física & 26 & 60,5 \\
Psicológica & 4 & 9,3 \\
Sexual & & \\
Episódios ${ }^{\mathbf{b}}$ (n=43) & 4 & 9,3 \\
De 1 a 4 agressões físicas & 9 & 20,9 \\
Mais de 4 agressões físicas & 6 & 14 \\
De 1 a 4 agressões psicológicas & 20 & 46,5 \\
Mais de 4 agressões psicológicas & 4 & 9,3 \\
De 1 a 4 agressões sexuais & & \\
Episódio mais recente (n=31) & 7 & 22,6 \\
Agressão física & 19 & 61,3 \\
Agressão psicológica & 1 & 3,2 \\
Agressão sexual & 3 & 9,7 \\
Agressões física e psicológica & 1 & 3,2 \\
Agressões física, psicológica e sexual & & \\
\hline
\end{tabular}

${ }^{b} \mathrm{O}$ quantitativo de tipo de violência sofrida e de episódios não é compatível com o número de mulheres prostitutas agredidas, pois, geralmente, em um único episódio estava presente mais de um tipo de agressão sofrida ou as mesmas mulheres, em momentos diferentes, sofreram tipos diferenciados de violência.

A prevalência do agravo violência na história de vida das prostitutas foi considerada elevada, $40,8 \%$, fato que pode repercutir na saúde mental, física e sexual das mesmas. As prostitutas estão mais sujeitas a sofrer violência por estarem expostas em lugares determinantes de atos violentos, onde podem ser vítimas de agressões verbais e físicas, tanto por parte de cidadãos comuns como de agentes policiais ${ }^{(13)}$.

Com relação à caracterização da violência física sofrida pelas prostitutas, dados como local, agressor e atendimento especializado são relevantes de serem identificados a fim de facilitar a elaboração de estratégias de prevenção de agravos a essa população. Os mesmos foram dispostos na tabela 3 .

$\mathrm{Na}$ trajetória de vida das prostitutas observa-se que, quando crianças, geralmente, são abusadas pelos pais ou parentes mais próximos; quando maiores, por seus parceiros, e em exercício da profissão, por seus clientes e empregadores ${ }^{(3)}$.
Tabela 3 - Distribuição percentual dos dados referentes ao último episódio de agressão física vivenciado pelas prostitutas entrevistadas. Picos-PI, set/out. 2010

\begin{tabular}{|c|c|c|}
\hline Caracterização da violência física & $\mathbf{N}$ & $\%$ \\
\hline \multicolumn{3}{|l|}{ Município da ocorrência $(n=11)$} \\
\hline Picos & 11 & 100 \\
\hline \multicolumn{3}{|l|}{ Local da ocorrência $(n=11)$} \\
\hline Residência & 4 & 36,4 \\
\hline Via pública & 6 & 54,5 \\
\hline Outros $^{\mathrm{c}}$ & 1 & 9,1 \\
\hline \multicolumn{3}{|l|}{ Forma de agressão $(n=11)$} \\
\hline Força corporal/espancamento & 10 & 90,9 \\
\hline Arma de fogo & 1 & 9,1 \\
\hline \multicolumn{3}{|l|}{ Agressor $(n=11)$} \\
\hline Amigos/conhecidos & 1 & 9,1 \\
\hline Cliente & 4 & 36,4 \\
\hline Ex-namorado(a) & 4 & 36,4 \\
\hline Namorado(a) & 2 & 18,1 \\
\hline \multicolumn{3}{|l|}{ Número de agressores envolvidos $(n=11)$} \\
\hline 01 & 11 & 100 \\
\hline \multicolumn{3}{|l|}{ Sexo do agressor $(n=11)$} \\
\hline Masculino & 10 & 90,9 \\
\hline Feminino & 1 & 9,1 \\
\hline Agressor fazia uso de álcool/drogas $(n=11)$ & 10 & 90,9 \\
\hline Vítima buscou atendimento $(n=11)$ & 2 & 18,1 \\
\hline \multicolumn{3}{|l|}{ Tipo de serviço $(n=2)$} \\
\hline Delegacia de Atendimento da Mulher & 1 & 50 \\
\hline Outras delegacias & 1 & 50 \\
\hline \multicolumn{3}{|l|}{ Tempo de procura pelo serviço $(n=2)$} \\
\hline Menos de $24 \mathrm{~h}$ & 1 & 50 \\
\hline 1 dia & 1 & 50 \\
\hline \multicolumn{3}{|l|}{ Atendimento realizado $(\mathrm{n}=2)$} \\
\hline Notificação da ocorrência & 2 & 100 \\
\hline \multicolumn{3}{|l|}{$\begin{array}{l}\text { Profissional que prestou o atendimento } \\
(n=2)\end{array}$} \\
\hline Delegada & 1 & 50 \\
\hline Policial & 1 & 50 \\
\hline \multicolumn{3}{|l|}{ Consequências sofridas $(n=11)$} \\
\hline Tentativas de suicídio & 1 & 9,1 \\
\hline Estresse pós-traumático & 1 & 9,1 \\
\hline Lesões físicas & 5 & 45,4 \\
\hline Nenhuma & 4 & 36,4 \\
\hline
\end{tabular}

'O termo outros incluiu a violência cometida em mata espessa.

Como identificado, as prostitutas são vítimas de diversos tipos de violência, tendo como agressor principal os próprios conhecidos. No entanto, os dados revelam que estes não são os únicos agressores, tendo em vista que essas mulheres ainda são vítimas do preconceito pela sociedade, em virtude da atividade que exercem. 


\section{DISCUSSÃO}

Observou-se no estudo uma frequência considerável de mulheres jovens, pois 50 (65,8\%) tinham até 30 anos. Em estudo realizado com 42 prostitutas em Fortaleza (CE), a faixa etária manteve-se entre 18 e 58 anos, sendo comum a existência de adolescentes $(11-26,2 \%)$ trabalhando nas ruas ${ }^{(15)}$. Percebe-se, dessa forma, que a prática do meretrício ainda atrai mulheres jovens, principalmente pela beleza e juventude peculiar a essa fase da vida.

No que concerne ao nível escolar dessas mulheres, o mesmo pode ter associação com o início da prática do meretrício ou às dificuldades encontradas para continuarem os estudos quando ingressam nesse mercado de trabalho. O presente estudo mostrou uma baixa escolaridade, com prevalência de até 11 anos de estudo, dados semelhantes a outra pesquisa realizada com 40 prostitutas de Sobral (CE), que apresentou 22 $(67 \%)$ mulheres com seis a onze anos de estudo ${ }^{(13)}$.

A prática do meretrício tem como uma das causas de ingresso as condições socioeconômicas, que podem levar algumas mulheres à prática duradoura de tal ofício. No entanto, percebe-se que nem sempre as condições de saúde e de vida, bem como financeira, melhoram. A prostituição é tida pelas prostitutas como uma profissão perigosa, mas de fácil exercício, pois ganha-se dinheiro sem muito esforço, sendo bem mais lucrativa que outras profissões que requerem baixa qualificação ${ }^{(2)}$.

Quanto ao tempo de exercício do meretrício, metade da amostra estudada tinha acima de 2 anos de exercício da prostituição, com relato de até 34 anos, o que mostra ser difícil sair do meretrício, principalmente devido às baixas condições socioeconômicas. Estudo realizado em Fortaleza (CE), com 81 prostitutas, revelou que 35 (43,2\%) mulheres estavam em atuação por um período de um a cinco anos, enquanto as demais, entre seis até mais de 30 anos, configurando uma longa permanência na prostituição ${ }^{(16)}$.

A partir da análise dos dados sobre a violência vivenciada pelas prostitutas, pode-se observar que quase metade das mulheres entrevistadas, 31 (40,8\%), afirmou ter sido vítima de algum tipo de agressão nos mais diversos ambientes. Estes resultados são compatíveis com os encontrados em outra pesquisa, na qual $20(47,6 \%)$ prostitutas foram vítimas de algum tipo de violência no domicílio, enquanto 17 (40,5\%) delas vivenciaram tal situação em ambiente de trabalho(15).

Percebe-se que as prostitutas podem ser vítimas de violência física, sexual e psicológica. No primeiro tipo, elas podem ser agredidas fisicamente por seu agressor com empurrões, espancamentos, queimaduras, uso de armas, dentre outras. Na violência sexual, são obrigadas ou ameaçadas a ter relação sexual contra sua vontade, bem como há imposição da prática de sexo anal ou oral sem o uso de camisinha. Já na violência psicológica, são vítimas de ameaças, gritos, humilhações e insultos ${ }^{(13)}$.

As prostitutas entrevistadas relataram que existe uma rejeição de vizinhos, familiares e amigos devido ao trabalho que exercem, o que as envergonha de seu ofício. Isso pode resultar no aparecimento de sintomas de depressão, expressado pelo alto consumo de álcool e drogas, e pelo isolamento ${ }^{(3)}$.
Quanto ao tipo de violência, percebeu-se predominância da agressão psicológica, 26 (60,5\%), seguida da violência física, $13(30,2 \%)$. O número de episódios mais frequentes foi mais de quatro agressões psicológicas, 20 (46,5\%). Em contrapartida, estudo desenvolvido por outros pesquisadores evidenciou a agressão física como a mais prevalente, $12(30 \%)^{(13)}$.

Quando indagadas em relação ao último episódio de agressão sofrida, a violência psicológica, isoladamente, foi a mais predominante, com $19(61,3 \%)$ relatos, seguida de violência física, com 7 (22,6\%). Cabe ressaltar que 4 (12,9\%) mulheres relataram que no último episódio foram vítimas de duas ou três agressões diferentes, totalizando 36 agressões sofridas nas 31 mulheres vítimas de violência.

Ao adentrar no âmbito da violência física, foco do presente estudo, notou-se que as agressões ocorreram mais prevalentemente no município de Picos-PI, com 11 (100\%) relatos, já que esta é a cidade de trabalho das mulheres entrevistadas. $\mathrm{O}$ local mais comum foi a via pública, 6 (54,5\%), sendo a força corporal/espancamento, a forma de agressão mais prevalente.

Quanto ao perfil do agressor, esses eram conhecidos das prostitutas, como ex-namorados, atuais parceiros ou mesmo amigos. O número predominante de agressores envolvidos nos episódios de violência física era somente um, sendo em sua maioria homens, que faziam uso de álcool e/ou outras drogas.

Pesquisas mostram que os agressores geralmente são conhecidos das vítimas. Estudo realizado em um núcleo de atendimento imediato à vítima de violência sexual de Sorocaba (SP), com 937 fichas de notificação, evidenciou que em 700 (76\%) os agressores eram identificáveis pelas vítimas ${ }^{(17)}$. Estudo revelou que nos ambientes domésticos e laborais, as prostitutas foram violentadas, respectivamente, por ex-companheiros, 12 $(60 \%)$, e por clientes, $6(35,3 \%)^{(14)}$. E no que concerne à violência conjugal, esta reflete uma concepção social de gênero, na qual o homem prevalece em posição superior à ocupada pela mulher, esperando sua subserviência e subordinação ${ }^{(18)}$.

Ainda durante a investigação, as prostitutas vítimas de violência física foram questionadas quanto à procura por algum serviço, e somente $2(18,1 \%)$ buscaram por este, sendo 1 $(50 \%)$ Delegacia Especializada de Atendimento à Mulher, e 1 $(50 \%)$ outras delegacias. Constata-se a infreqüente denúncia da violência sofrida por este grupo de mulheres, que, talvez, por sentirem-se excluídas socialmente, sentem-se também excluídas de serem merecedoras do direito de denunciarem uma agressão sofrida ${ }^{(19)}$.

No Brasil, existem atualmente diversos serviços especializados no atendimento de vítimas de violência, são eles: Delegacias Especializadas de Atendimento à Mulher (DEAM), Centros de Referência de Atendimento às Mulheres em Situação de Violência, Defensorias Públicas da Mulher, Casas Abrigo, Juizados de Violência Doméstica e Familiar contra a Mulher, bem como Centros de Referência de Assistência Social (CRAS) e Centros de Referência Especializados de Assistência Social (CREAS)(20).

Em relação ao tempo de procura pelo serviço, 1 (50\%) entrevistada levou menos de 24 horas para efetivar a denúncia, e $1(50 \%)$, um dia. O atendimento prestado foi somente a notificação da agressão sofrida. Tais achados vão ao encontro de uma pesquisa que revelou que depois de violentadas, 
$10(25 \%)$ prostitutas entrevistadas não tomaram nenhuma atitude, $7(17,5 \%)$ revidaram com violência física e $4(10 \%)$ fugiram do agressor ${ }^{(13)}$.

Dentre as consequências sofridas, esteve mais prevalente a variável lesões físicas, $5(45,4 \%)$, enquadrado nesta categoria hematomas e arranhões conforme respondido pelas entrevistadas. Foi comum também a não existência de consequências após a agressão, 4 (36,4\%). No entanto, sabe-se que as formas de violência cometidas às prostitutas, consequentemente, causam-Ihes danos à saúde, trazendo sequelas físicas e mentais ${ }^{(13)}$.

Em suma, como observado pelo estudo, a situação das prostitutas atuantes no município de Picos-PI é repleta de riscos e vulnerabilidades, entre eles a violência. Assim, torna-se necessário implementar os direitos dessas mulheres vítimas de violência, independente de questões sociais e culturais, bem como estimular a participação das mesmas na promoção de uma cultura de paz e na denúncia de seus agressores.

\section{CONCLUSÕES}

Tendo em vista o objetivo proposto no início da pesquisa, os resultados foram esclarecedores e levaram a afirmar que é comum a ocorrência de violência em mulheres prostitutas, já que trabalham em lugares determinantes de atos violentos. No entanto, vale ressaltar que embora a violência física esteja presente na realidade de parte dessas mulheres, a mesma não se configurou como prevalente, pois atos de constrangimentos, ofensas e insultos foram os mais relatados pelas vítimas.

Observou-se que as prostitutas eram solteiras, pertenciam a um grupo socioeconômico desfavorável e possuíam baixo nível de escolaridade, o que dificultava a inserção das mesmas em outras atividades comerciais.

Notou-se também que essas mulheres estão sujeitas à violência, seja por seus clientes, que entendem que o pagamento Ihes confere poderes, até mesmo para agredi-las, bem como pela sociedade, que as marginalizam como sendo pessoas não dignas de direitos. Cabe ressaltar como fator preocupante a pouca procura, enquanto vítimas de violência, pelos serviços jurídico, policial e de saúde, seja por medo da recidiva das agressões ou pela vergonha. Sendo assim, torna-se imprescindível a divulgação das ações de apoio realizadas por esses órgãos, a fim de que as prostitutas exercitem seus direitos.

Assim, torna-se necessário implementar os direitos dessas mulheres vítimas de violência, independente de questões sociais e culturais, bem como estimular a participação das mesmas na promoção de uma cultura de paz e na denúncia de seus agressores. Diante disso, torna-se fundamental a elaboração de projetos com vistas à prevenção da violência e promoção da saúde neste grupo de mulheres, bem como capacitações que permitam aos profissionais de saúde, principalmente aos enfermeiros, estarem mais sensibilizados e preparados a atendê-las enquanto cidadãs merecedoras de direitos e vítimas sociais.

\section{REFERÊNCIAS}

1. Moraes MLC, Costa PB, Aquino PS, Pinheiro AKB. Educação em saúde com prostitutas de Fortaleza: relato de experiência. Rev Eletrônica Enferm 2008;10(4):1144-51.

2. Guimaraes K, Merchan-Hamann E. Comercializando fantasias: a representação social da prostituição, dilemas da profissão e a construção da cidadania. Rev Estud Fem 2005;13(3):525-44.

3. Amaya A, Canaval GE, Viáfara E. Estigmatización de las trabajadoras sexuales: influencias en la salud. Colomb Med 2005;36(3):65-74.

4. Ribeiro FMV. Casas de prostituição e o circuito sexual das prostitutas de luxo no Nordeste. In: Anais do XI Congresso Luso Africano Brasileiro de Ciências Sociais; 2011 ago 1-12; Salvador, Bahia. Salvador: Universidade Federal da Bahia; 2011.

5. Ministério da Saúde. Prevenção e tratamento dos agravos resultantes da violência sexual contra mulheres e adolescentes. Brasília: Ministério da Saúde; 2005.

6. Saffioti HIB. Gênero, patriarcado, violência. São Paulo (SP): Fundação Perseu Abramo; 2004.

7. Ministério da Saúde. Atenção integral para mulheres e adolescentes em situação de violência doméstica e sexual. Brasília: Ministério da Saúde; 2006.
8. Brasil. Lei $n^{\circ} 11.340$ de 7 de agosto de 2006. Cria mecanismos para coibir a violência doméstica e familiar contra a mulher. Diário Oficial da União 8 de agosto de 2006.

9. Ministério da Saúde, Secretaria de Políticas de Saúde. Violência intrafamiliar. Brasília: Ministério da Saúde; 2006.

10. Garcia-Moreno C, Jansen HA, Ellsberg M, Heise L, Watts, $\mathrm{CH}$. Prevalence of intimate partner violence: findings from the WHO multi-country study on women's health and domestic violence. Lancet 2006; 368(9543):1260-9.

11. D'Oliveira AFPL, Schraiber LB, França-Junior I, Ludermir $A B$, Portella AP, Diniz CS et al. Fatores associados à violência por parceiro íntimo em mulheres brasileiras. Rev Saúde Pública 2009;43(2):299-310.

12. Marinheiro ALV, Vieira EM, Souza L. Prevalência da violência contra a mulher usuária de serviço de saúde. Rev Saúde Pública 2006;40(4):604-10.

13. Ximenes Neto FRG, Oliveira JS, Rocha J. Violência sofrida pelas profissionais do sexo durante seu trabalho e as atitudes tomadas após serem vitimadas. REME Rev Min Enferm 2007;11(3):248-53.

14. Oliveira CC, Fonseca RMGS. Práticas dos profissionais das equipes de saúde da família voltadas para as mulheres em situação de violência sexual. Rev Esc Enferm USP 
2007;41(4):605-12.

15. Aquino PS. Desempenho da atividade de vida por prostitutas. Fortaleza. Dissertação [Mestrado em Enfermagem]Universidade Federal do Ceará. Programa de Pós- Graduação em Enfermagem; 2007.

16. Aquino PS, Nicolau AIO, Moura ERF, Pinheiro AKB. Perfil sociodemográfico e comportamento sexual de prostitutas de Fortaleza - CE. Texto \& Contexto Enferm 2008;17(3):427-34.

17. Campos MAMR, Schor N. Violência sexual como questão de saúde pública: importância da busca ao agressor.
Saúde Soc 2008;17(3):190-200.

18. Alves SLB, Diniz NMF. "Eu digo não, ela diz sim": a violência conjugal no discurso masculino. Rev Bras Enferm 2005;58(4):387-92.

19. Penha JC. Violência contra a mulher: riscos e vulnerabilidades de prostitutas picoenses. Picos (PI). Monografia [Graduação em Enfermagem]- Universidade Federal do Piauí; 2010.

20. Ministério da Saúde. Balanço de ações 2006-2007: enfrentamento à violência contra a mulher. Brasília: Ministério da Saúde; 2007. 